\title{
El administrador provisional de establecimientos educacionales en el sistema escolar chileno: ¿Es útil esta técnica de intervención administrativa?
}

\author{
The provisional manager of educational centers in the Chilean school system: \\ Is this technique of administrative intervention useful?
}

\author{
Carlos Rivera Hernández \\ Abogado, Chile
}

\begin{abstract}
RESUMEN En este artículo se analizan las principales normas de la Ley 20.529 que regulan la figura del administrador provisional de establecimientos subvencionados o que reciban aportes del Estado. Sugiere que la limitada configuración legal del referido interventor deviene en la pérdida de su eficacia normativa y práctica, impactando negativamente en la gestión administrativa y política de los órganos administrativos del sector. En tal sentido, se plantea que la deficiente técnica legislativa empleada en el diseño de esta figura de administración provisional produce que los actores del sistema escolar no comprendan adecuadamente su verdadera naturaleza y finalidad pública.
\end{abstract}

PALABRAS CLAVE Intervención administrativa, administrador provisional, técnica legislativa, efectividad normativa.

ABSTRACT In the present work the main norms of the Law 20,529 are analyzed, which regulate the figure of the provisional administrator of subsidized establishments or who receive contributions from the State. It suggests that the limited legal configuration of said financial controller results in the loss of its normative and practical effectiveness, negatively impacting the administrative and political management of the administrative organs of the sector. In this sense, it is argued that the deficient legislative technique used in the design of this figure of Provisional Administration in school matter, causes that the actors of the school system do not adequately understand its true nature and public purpose.

KEYWORDS Administrative intervention, provisional administrator, legislative technique, normative effectiveness. 


\section{Introducción}

Es posible afirmar que el administrador provisional establecido en la Ley 20.529, cuyo objeto general es dar protección a un bien jurídico de la mayor relevancia en nuestra Constitución Política, como es la educación, es una institución jurídico-administrativa, en general, desconocida en el sistema escolar, a pesar de gozar de existencia legal previa, pero muy inmediata, en la Ley 20.184, ${ }^{1}$ que agregó un artículo único, el artículo 52 bis, al Decreto con Fuerza de Ley 2 de 1998, del Ministerio de Educación, en su texto refundido, coordinado y sistematizado fijado por el Decreto 40, de 2006, de la misma Secretaría de Estado.

Una de las causas de la escasa visibilidad del actual administrador puede atribuirse razonablemente a su pacífica tramitación parlamentaria, considerando además que fue solo parte de una ley que creó todo un sistema de aseguramiento de la calidad. Un asunto no menor es que tampoco los preceptos de esta ley que regulan a este interventor fueron impugnados originalmente en el Tribunal Constitucional. ${ }^{2}$ Esta situación contrasta con un hecho público y notorio: el intenso debate público que produjo la tramitación del proyecto de ley de Administrador Provisional y de Cierre en Educación Superior, ahora Ley 20.800, normativa que, como sabemos, se generó a raíz de los graves problemas detectados en la Universidad del Mar y en la Universidad Arcis. ${ }^{3}$

Por su parte, en la doctrina la situación no es muy diferente, a pesar de que este tipo de interventores administrativos, como se verá más adelante, existen en nuestro país y se aplican actualmente en diversas materias, principalmente en los mercados regulados. Este desinterés de la academia se manifiesta en un hecho concreto, a saber: no fue posible encontrar artículos académicos sobre esta técnica específica de poli-

1. En este trabajo solo se considerará como marco temporal lo ocurrido desde el año 199o hasta el año en curso. Señalado esto, es posible afirmar que la existencia jurídica de esta figura, en materia educativa, data del año 2007; ello en virtud de la Ley 20.180, que introdujo un artículo único al Decreto con Fuerza de Ley 2, de Subvenciones del Estado a Establecimientos Educacionales.

2. Esto queda de manifiesto en la sentencia del Tribunal Constitucional rol 2731-14, considerando sexagésimo, cuando se objeta la modificación que el proyecto de ley de Administrador Provisional y de Cierre en Educación Superior introduce al artículo 89 de la Ley 20.529, incorporando una nueva causal para nombrar administrador provisional en establecimientos de enseñanza básica y media. El Tribunal señala que: «la modificación que se objeta es una causal más para nombrar un administrador provisional. Las otras cinco causales también se aplican a los establecimientos municipales. Y cuando se ejerció el control preventivo del artículo 89, que se modifica, no fue considerado como propio de ley orgánica constitucional (STC 2009/2011)».

3. La figura del administrador provisional fue propuesta luego de la crisis de la Universidad del Mar el año 2012 por parlamentarios de distintos sectores. Así lo consigna el Boletín 8364-04, de los diputados Pepe Auth, Cristina Girardi, Mario Venegas y Carolina Goic, Alejandra Sepúlveda y Lautaro Carmona. Y también el Boletín 8775-04, moción de los senadores Zaldívar, Lagos y Walker, que proponen un proyecto de ley para asegurar la continuidad de prestación del servicio educativo en el caso de instituciones de educación superior expuestas a la cancelación de su personalidad jurídica y pérdida del reconocimiento oficial. 
cía administrativa. Y la jurisprudencia de los Tribunales Superiores de Justicia ${ }^{4}$ y de la Contraloría General de la República (CGR), ${ }^{5}$ tampoco puede citarse como una fuente significativa de información.

En virtud de lo anterior, parece pertinente y necesario comenzar a investigar sobre esta técnica de intervención administrativa, inserta en la normativa educacional. ${ }^{6}$ En este contexto, es menester señalar que la hipótesis de este trabajo se enfoca en un ámbito más bien específico: sugiere que la deficiente técnica legislativa utilizada en la configuración de este interventor educativo redunda (y redundará) en la pérdida de su eficacia normativa.

4. La Municipalidad de Lonquimay recurrió de protección (véase la sentencia de la Corte de Apelaciones de Santiago rol 75921-2015) en contra de la Superintendencia de Educación, a raíz del nombramiento de un administrador provisional en la escuela Malalmahuida. La Corte de Apelaciones de Santiago desestimó el recurso en base al artículo 54 de la Ley 19.880, pues existía un recurso del municipio pendiente ante la administración. La Corte Suprema confirmó la sentencia apelada (sentencia de la Corte Suprema rol 21173-2015).

5. Existe poca jurisprudencia administrativa de la CGR sobre el interventor temporal de la Ley 20.529, pero no obstante aquello, resulta ser muy interesante. Así, el dictamen 10.351, de 2016, se pronuncia sobre diversos aspectos que derivan del carácter de empleador que posee el administrador provisional. Otro, el núm. 10.213, de 2017, se refiere a una consulta que el Superintendente de Educación (s) realiza al ente contralor, en orden a «si se ajusta a derecho que esa repartición designe un administrador provisional para cada uno de los establecimientos educacionales que dependen de un sostenedor municipal,» señalando el máximo órgano contralor que «encontrándose la consulta de que se trata en el ámbito de competencia de esa autoridad administrativa, esta Entidad de Control no advierte inconvenientes para que aquella decida efectuar o no la designación en cuestión, en ejercicio de la facultad que el legislador colocó dentro de la esfera de sus atribuciones». Un tercer dictamen (26.131 de 2017) resulta ser muy relevante, pues determina el órgano contralor que el «administrador provisional del artículo 87 de la Ley 20.529 puede tener a su cargo más de un centro de enseñanza». Y durante 2018 existen otros dos pronunciamientos, el núm. 1.323, donde reitera lo señalado en el pronunciamiento 26.131, y finalmente tenemos el núm. 17.591, que es de la mayor importancia para este artículo, pues deja meridianamente claro que aunque concurran las causales que habilitan a la autoridad administrativa a proceder, el Superintendente de Educación «puede nombrar un administrador provisional». Es decir, es una facultad que la autoridad posee y aunque se encuentre ante la configuración de alguna causal que habilite su nombramiento, puede decidir no ejercerla. Y puede haber más de una razón para no actuar, pues, en general, dicen relación con el análisis fáctico que la autoridad realiza de la situación. Así, en el mentado dictamen se indica: «consultada al efecto la Superintendencia de Educación, esta ha señalado que en el caso de los establecimientos educacionales administrados por la referida Corporación, si bien se cumplía con una de las causales objetivas indicadas en la ley para la designación de un administrador provisional, y concurría el consiguiente riesgo o entorpecimiento en la continuidad del año escolar, la gestión de dicho administrador resultaba inviable, producto de la evidente falta de financiamiento que mantenía la Corporación al momento de la pertinente evaluación». Y esos son los dictámenes que a la fecha ha emitido la CGR. Los demás pronunciamientos encontrados se refieren al administrador provisional que se estableció en el Decreto Ley 8.143, de 1980, del Ministerio de Educación (Dictámenes de la Contraloría General de la República 27.348, de 2002 y 32.380, de 2008). Hay otro (Dictamen de la Contraloría General de la República 37.723, de 2009) que se pronuncia además sobre el ámbito de aplicación temporal del administrador provisional que la Ley 20.180, mediante el artículo único 52 bis, que incorporó al D.F.L. 2, de 1998, del Ministerio de Educación.

6. Se estudian las normas específicas de la regulación de esta figura administrativa (que va de los artículos 87 al 98 de la Ley 20.529) y que se relacionan directamente con el objeto de este artículo. 
Para sustentar esta tesis, en primer lugar, se estudiarán las características, en general, del administración provisional en el derecho chileno. En segundo lugar, se revisarán las normas pertinentes de la Ley 20.529, que regulan y estructuran este interventor, señalando las debilidades institucionales de las que adolece, en virtud de una deficiente técnica legislativa. Y, en tercer lugar, se realizará una breve comparación normativa con la más nueva de las figuras de intervención en educación, el Administrador Provisional y de Cierre de Instituciones de Educación Superior, regulado en la Ley 20.880. Debemos señalar que en el trabajo se hará referencia a un caso real y público de solicitud de nombramiento de administrador provisional con el objeto primero de realizar su exposición, para luego ir verificando, en base a él, muchas de las afirmaciones que se realizarán.

\section{Contexto en el cual se sitúa el administrador provisional de la Ley 20.529}

Esta técnica de intervención es utilizada por el legislador desde 1997 (artículo 24 del Decreto con Fuerza de Ley núm. 3 de 1997, del Ministerio de Hacienda de Chile 3). El Tribunal Constitucional señaló (sentencia rol 2731-14, considerando segundo) que su ámbito de aplicación ha sido respecto de empresas que operan bajo la modalidad de contratos administrativos, ${ }^{7}$ como de empresas que operan bajo régimen de autorización. ${ }^{8}$

Por otra parte, al revisar las respectivas normas regulatorias, podemos apreciar que tiene distintas denominaciones según la actividad en que interviene: como Inspector Delegado (Ley de Bancos y AFP), Interventor (Ley Eléctrica y la Ley de Concesiones del Ministerio de Obras Públicas), y desde luego, Administrador Provisional (transportes, servicios sanitarios, pensiones, isapres y educación).

\section{Características generales}

El administrador provisional:

- Tiene por objeto resguardar los intereses de terceros ajenos a los dueños de las empresas o establecimientos afectados.

- Se designa en situación de crisis de éstas: liquidación, caducidad, quiebra, mala

7. Así, en empresas sujetas a contratos administrativos, existe en materia eléctrica (Decreto con Fuerza de Ley 4 de 2007 del Ministerio de Economía), en materia sanitaria (Decreto con Fuerza de Ley 382 de 1989 del Ministerio de Obras Públicas), en materia de concesiones de obras públicas (Decreto Supremo 900 de 1996 del Ministerio de Obras Públicas de Chile), y en materia de transporte público de pasajeros (Ley 18.696 de 1988).

8. En materia de empresas sujetas a autorización, existe respecto de los bancos (Decreto con Fuerza de Ley 3 de 1997 del Ministerio de Hacienda), de las AFP (Decreto Ley 3.500 de 1980), de las isapres (Decreto con Fuerza de Ley 1 de 2006 del Ministerio de Salud de Chile), en establecimientos educacionales de enseñanza básica y media (Ley 20.529 de 2008) y en establecimientos educacionales de educación superior (Ley 20.800 de 2014). 
calidad de servicio (artículo 89 de la Ley 20.529), ${ }^{9}$ compromiso de fondos de terceros, riesgo patrimonial.

- Con el propósito de intentar corregir lo que los propietarios no pueden llevar a cabo, porque tienen conflictos entre sus intereses de propietarios y los derechos de los terceros. Una característica esencial es que reemplaza a la administración que puso el dueño, con el propósito de dar continuidad al servicio, mejorarlo o salvar la institución de su disolución sin poner en cuestionamiento su propiedad. Su designación es temporal y se sujeta a rigurosas reglas de rendición de cuentas.

- Es una medida excepcional. ${ }^{10}$ De ahí que requiera autorización del legislador, causales estrictas y, en general, un procedimiento de reclamo jurisdiccional. ${ }^{11}$

\section{Concepto y características propias del administrador provisional regulado por la Ley 20.529}

\section{El artículo 87 de la Ley 20.529 establece:}

La Superintendencia, mediante resolución fundada, podrá nombrar un administrador provisional para que asuma las funciones que competen al sostenedor de un establecimiento educacional subvencionado o que reciba aportes del Estado, con el objeto de asegurar el adecuado funcionamiento de dicho establecimiento y la continuidad del servicio educativo. El administrador provisional durará en su cargo sólo hasta el término del año escolar en curso, salvo lo establecido en el inciso segundo del artículo 94.

Como ya se señaló, el antecedente inmediato de las normas de la Ley 20.529, que regula el nuevo administrador provisional, es la Ley 20.184 de $2007 .{ }^{12} \mathrm{Si}$ se analizan

9. Señala que «sólo se podrá nombrar un administrador provisional en los siguientes casos: a) Cuando el establecimiento educacional se mantenga en la categoría de Desempeño Insuficiente por cuatro años consecutivos $[\ldots] »$.

10. Siempre se trata de una medida excepcional, que procede ante causales tasadas legalmente, dado que significa una intensa restricción a los derechos del particular que desarrolla la actividad. Es decir, el legislador reconoce siempre que ha de ser una medida proporcionada a la gravedad por él mismo calificada. Por esa razón corresponde aplicar un principio rector de toda intervención pública: la proporcionalidad.

11. No obstante, en el caso de la figura en estudio de la Ley 20.529, la ley solo estable una instancia administrativa. Así, en el artículo 89, inciso penúltimo, señala: «Dicho nombramiento se notificará por carta certificada al sostenedor para que éste, dentro del plazo de cinco días hábiles contados desde dicha notificación, pueda reclamar administrativamente ante el Superintendente de esa designación».

12. El propósito del proyecto queda establecido en la Historia de la Ley, en donde el diputado informante Gonzalo Duarte (DC) señala: «En los últimos días hemos podido conocer las dificultades que enfrentan los alumnos de los diversos Colegios Britania. Este no es un hecho aislado como pudimos apreciar durante los últimos meses. En ocasiones algunos sostenedores no dan cumplimiento a sus obligaciones y los alumnos y profesores se ven enfrentados a situaciones de tanta gravedad como el hecho de que los alumnos no tengan agua en su establecimiento, lo que atenta no sólo contra la posibilidad de educarse adecuadamente, sino que va en contra de su salud y, en definitiva, atenta en contra de la dignidad de nuestros jóvenes y el 
ambas figuras, podemos apreciar que sus causales de procedencia son de redacción muy similar, con la diferencia de que el administrador de la Ley 20.529 contempla una causal relacionada con el rendimiento académico del establecimiento, la que se revisará más adelante.

\section{Características principales del administrador provisional de la Ley 20.529}

1) Sólo interviene en la prestación del servicio público educacional. En efecto, se excluyen los establecimientos educacionales no financiados con recursos públicos. Lo anterior se debe a la lógica particular con que opera el sector educacional, ${ }^{13}$ pues estos establecimientos son los menos regulados de la educasción formal, no obstante, la continuidad del servicio educativo de los estudiantes de los referidos establecimientos se garantiza mediante otras técnicas de intervención administrativa. ${ }^{14}$

2) Es uno de los administradores provisionales más intensamente regulados por la ley, lo que no significa necesariamente que su regulación sea adecuada desde una perspectiva de su técnica legislativa. ${ }^{15}$ El legislador trató de ser muy minucioso al regular la intervención de este administrador. En consecuencia, existe poco espacio para la regulación administrativa. Sin embargo, y como se verá, esta detallada regulación no necesariamente implicó una regulación normativa adecuada y eficaz. Lo anterior abre márgenes más o menos amplios de interpretación de sus normas.

adecuado desarrollo de la acción educativa. El proyecto pretende contribuir a la solución de situaciones como la descrita y para ello propone otorgar al Ministerio de Educación la facultad de nombrar administrador provisional para garantizar el término del año escolar de los establecimientos educacionales, cuando concurra alguna de las siguientes causales: cesación de pagos de las remuneraciones; suspensión de los servicios básicos para el funcionamiento del local escolar, como agua, luz, etc.; embargo del mobiliario o del local de funcionamiento y/o incumplimiento reiterado de las obligaciones del sostenedor» (BCN, 2018a: 4-5). Debemos considerar un asunto no menor, y que explica la naturaleza de este administrador: los Colegios Britania fueron establecimientos particulares subvencionados.

13. Un ejemplo de lo que acabamos de afirmar es el caso de la atribución de la Superintendencia de Educación establecida en el artículo 49, letra d) de la Ley 20.529. Esta norma permite a los fiscalizadores del servicio «ingresar a los establecimientos educacionales y dependencias del sostenedor», pero el inciso segundo de la misma señala: «Respecto de los establecimientos educacionales particulares pagados, el ejercicio de esta atribución exigirá la existencia de una denuncia o reclamo».

14. Por ejemplo, el artículo 49, letra k) de la Ley 20.529, en relación con el inciso segundo de la letra d) del mismo artículo, permite a los fiscalizadores ingresar en el caso de que lo hagan para verificar los requisitos del reconocimiento oficial, sin necesidad de denuncia. La letra d), inciso segundo, expresa: «Respecto de los establecimientos educacionales particulares pagados, el ejercicio de esta atribución exigirá la existencia de una denuncia o reclamo conforme al párrafo $4 .^{\circ}$ de este Título, salvo que se trate de la verificación del cumplimiento de los requisitos exigidos para mantener el reconocimiento oficial del Estado o del título preliminar del Decreto con Fuerza de Ley 2, de 2009, del Ministerio de Educación».

15. El Tribunal Constitucional, en la sentencia rol 2731-14, considerando cuarto, expresa: «Que el administrador provisional que diseña el proyecto sigue muy de cerca al administrador provisional establecido en materia de isapres (Ley 19.895) y el creado en materia de educación escolar (Ley $\mathrm{N}^{\circ} 20.529$ ). Pero es lejos el administrador más regulado que pueda existir en nuestro sistema jurídico (...)» 
3) Su nombramiento es facultativo o discrecional. ${ }^{16}$ El Superintendente puede ejercer esta atribución cuando se configura alguna de las causales legales, pero no está obligado por la concurrencia de esa sola circunstancia. En efecto, se trata de una potestad reglada en cuando a su ejercicio, pero discrecional en su procedencia. ${ }^{17}$ Dicha discrecionalidad se explica en la necesaria concordancia que debe existir entre las causales del nombramiento y el cumplimiento de su objeto. En este sentido la evaluación que la autoridad debe realizar debe considerar no solo la observancia de los hechos que sustentan las causales, sino que esta administración excepcional sea útil y congruente con el fin establecido en la normativa.

4) Su nombramiento es excepcional o de última ratio, de ahí que requiera autorización del legislador, causales estrictas y un procedimiento de reclamo, en este caso administrativo, estando su designación a cargo de autoridades administrativas o políticas superiores. Y en este caso específico lo designa el Superintendente de Educación. ${ }^{18}$ Esta característica también implica que la Superintendencia de Educación deberá necesariamente recurrir de manera previa a cualquier otra facultad que posea para tratar de mejorar los problemas del establecimiento, antes de recurrir al nombramiento de un administrador provisional.

5) Es nombrado por una autoridad fiscalizadora, de perfil técnico. El legislador parece haber decidido que, en el ámbito de aplicación de la Ley 20.529, la decisión sobre la procedencia de la designación del administrador provisional se radique en una autoridad fiscalizadora, de carácter más técnico, lo que hace suponer que la finalidad que se tuvo a la vista fue resguardar que su designación siempre estuviese amparada en razones objetivas y técnicas, para mejor y mayor resguardo del interés público. ${ }^{19}$

6) Opera en virtud de una autorización administrativa. Como ya se señaló, el ámbito general de aplicación de este tipo de interventores en Chile ha sido respecto de empresas bajo la modalidad de contratos administrativos o bajo régimen de autorización. En este sentido, y según la mentada jurisprudencia del Tribunal Constitucional, la forma de actuación estatal aplicable en el ámbito educativo es la autorización,

16. El artículo 16 señala: «Sólo se podrá nombrar un administrador provisional en los siguientes casos $[\ldots] »$. De esta manera, el adverbio «sólo» nos indica que las causales son taxativas, y, por su parte, el verbo «podrá» otorga el carácter discrecional a la facultad en estudio.

17. Lo señalado redunda en una enorme presión sobre la autoridad administrativa, pues las comunidades escolares, al verificar la existencia de causales, comienzan en muchos casos a exigir su nombramiento, no comprendiendo necesariamente las variables fácticas que la autoridad debe analizar antes de proceder, ni las consecuencias de su nombramiento.

18. El artículo 89, inciso final, establece: «El nombramiento del administrador provisional será una atribución privativa e indelegable del Superintendente».

19. Resulta evidente que la administración provisional se funda en expresas consideraciones de interés público. Este interventor debe tratar de realizar una administración que restituya un mínimo equilibrio de los derechos fundamentales amagados por una mala administración, que llevó al establecimiento a una crisis, y dar continuidad del servicio educacional hasta el término del año escolar. 
manifestada en concreto, bajo la figura del reconocimiento oficial. ${ }^{20}$ Así, el Tribunal ha señalado:

Jurídicamente, el reconocimiento oficial es una autorización [...] el particular interesado en obtenerla debe suministrar a la administración una serie de antecedentes destinados a evitar que ciertos riesgos, considerados como potencialmente lesivos al interés público, se materialice (sentencia del Tribunal Constitucional rol 2731-14, considerando decimoprimero).

7) En virtud de lo anterior, la autorización «implica un intenso control preventivo» (sentencia del Tribunal Constitucional rol 2731-14, considerando decimoprimero). ${ }^{21}$

\section{Caso de análisis: Colegio San Nicolás de Independencia}

El caso real que se presenta se utilizará en lo sucesivso para ir ilustrando con un ejemplo concreto las diversas debilidades que el administrador provisional presenta en su configuración legal.

\section{Antecedentes del establecimiento educacional}

El Colegio San Nicolás, $\mathrm{RBD}^{22}$ 10.237-7, está ubicado en Gamero 541, comuna de Independencia. Su dependencia y naturaleza es la de un colegio particular subvencionado. Contaba con 13 docentes en su planta y tenía, a la fecha de la ocurrencia de los hechos, 158 estudiantes matriculados.

\section{Los hechos}

El sitio web de la radio Biobío informó de la siguiente manera los hechos:

Un grupo de profesores y apoderados del Colegio San Nicolás de Independencia decidieron tomarse el recinto en protesta por el cierre del establecimiento a un mes del inicio del año escolar. La medida de presión ocurre luego de que la sostenedora del recinto, María Eliana Cox, informara al Ministerio de Educación el cierre del recinto el pasado 29 de enero a través de un documento.

20. El artículo 45 indica que el «reconocimiento oficial del Estado es el acto administrativo en virtud del cual la autoridad confiere a un establecimiento educacional la facultad de certificar válida y autónomamente la aprobación de cada uno de los ciclos y niveles que conforman la educación regular, y de ejercer los demás derechos que le confiere la ley».

21. En este sentido, Juan Carlos Ferrada y Flavio Quezada levantan una muy interesante tesis. Creen que la educación, por las razones de orden público, ha sido publificada mediante el reconocimiento oficial de establecimientos educacionales. Y en esta misma lógica, es razonable plantear que «la educación formal, no así la informal y no formal, para mayor resguardo del interés público concernido, ha sido publificada» y esto se materializaría «a través del denominado «reconocimiento oficial de establecimientos educacionales», técnica de intervención utilizada en este caso» (Ferrada y Quezada, 2017: 175).

22. RBD corresponde a la sigla de Rol Base de Datos, número identificador de los establecimientos educacionales ante el Ministerio de Educación. 
En diálogo con el medio Biobío Chile, el presidente del Centro de Padres del colegio, Enzo Gutiérrez, indicó que la toma de los profesores, además del cierre, se genera por «bonos que no se pagaron, pero que fueron cobrados al Ministerio [...] comentó que acudieron al Ministerio de Educación para buscar alguna solución a esta difícil situación. «Nos han dado la opción de poder reubicar a nuestros niños, pero como grupo de padres no queremos tomar esa opción [...] Somos un colegio chiquitito, hemos creado una comunidad y es lo que queremos defender». Eso sí, detalló que la cartera «nos ha brindado una pequeña luz de esperanza, que es que el grupo de Centro de Padres se convierta en una corporación de educación sin fines de lucro». ${ }^{23}$

La diputada Karol Cariola y el alcalde de la comuna de Independencia, Gonzalo Durán, intercedieron en el conflicto, apoyando a los apoderados y a los estudiantes, y realizando diversas gestiones ante las autoridades educativas. Así lo informó el diario La Nación:

Los acompañaron en la ocasión el alcalde Gonzalo Durán (PS) y la diputada PC Karol Cariola, quienes junto a la comunidad escolar insistieron en la petición de que se nombre a un administrador provisional con el objetivo de que el plantel pueda seguir funcionando por lo menos un año (La Nación, 2016) ${ }^{24}$

Por otra parte, el abogado de los apoderados, Rodrigo Logan, procedió además a interponer una acción de protección ante la Corte de Apelaciones de Santiago (rol 17.538-2016), solicitando la reapertura judicial del Colegio y el nombramiento de un administrador provisional por parte del Superintendente de Educación. El día 8 de marzo de 2016, el abogado presentó ante la Corte un «téngase presente», en donde informa que «al día de hoy hay constancias de que la actual sostenedora del establecimiento ha procedido a desmantelar el inmueble en donde se encuentra el colegio. ${ }^{25}$

En la intervención que realiza el dirigente del Centro de Padres del Colegio San Nicolás, Jorge Barrales, en la Comisión de Educación de la Cámara de Diputados, el día 8 de marzo de 2016, queda claro cuál es el verdadero propósito de sus representados respecto al futuro del establecimiento, y la razón efectiva por la cual, además, están solicitando el administrador provisional. En el video oficial del canal de televisión de la Cámara de Diputados se puede ver y escuchar lo siguiente:

Hablar de que el proyecto educativo no es viable y que la mejor solución sea cambiar a los niños... creo que es un poco ortodoxa [...] porque si este colegio puede ser un pionero en solucionar un problema que a lo mejor se les va a venir con la reforma de educación de aquí a final de año [...] porque no sabemos cuántos colegios que están igual que el San Nicolás van a cerrar. ${ }^{26}$

23. Leonardo Rubilar, «Profesores se toman colegio para revertir su cierre: 300 niños quedarían sin estudiar», Biobio Chile, 17 de febrero de 2016, disponible en http://bit.ly/2Fb4Zea.

24. Patricia Schüller, «Comunidad escolar del colegio san Nicolás organizó «simbólico» ingreso a clases», La Nación, 3 de marzo de 2016, disponible en http://bit.ly/2FegDZo.

25. Véase el documento en el sitio web del Poder Judicial de Chile, disponible en http://bit.ly/2SFzvQz. 26. Video del canal de televisión de la Cámara de Diputados, disponible en http://www.cdtv.cl/Progra- 
La conclusión es evidente e ineludible. Los apoderados pidieron la designación de un administrador provisional para, de esta manera, evitar el cierre inminente del establecimiento. Pero su idea no era la continuidad del servicio educativo solo hasta fines de ese año. Su intención era seguir con el proyecto educativo más allá del término del año escolar, continuando con el proyecto de Colegio bajo otra figura legal. Pero lo que los apoderados y la comunidad educativa no sabían es que, y como se verá más adelante, en ninguna hipótesis el administrador provisional de la Ley 20.529, en el caso de un establecimiento particular subvencionado, es realmente provisional, sino que, por el contrario, es de cierre, por lo que su designación no es útil para sus propósitos.

Finalmente, mediante el oficio ordinario núm. 409, del 22 de abril de 2016, el Superintendente de Educación responde al Jefe de Gabinete de la Subsecretaria de Educación, respecto a la petición de la diputada Cariola, que solicita designar un administrador provisional en el referido Colegio. En el número 7 del documento referido se señala:

En relación con la solicitud de evaluar la posibilidad de designar un administrador provisional [...] informamos que, mediante Oficio ORD. 0402, del 20 de abril de 2016, se emitió un pronunciamiento, con motivo de una anterior presentación de la H. Diputada Cariola, compartiendo el criterio de la Directora Regional (s) Metropolitana [...] en orden a señalar que el nombramiento de un administrador provisional en los términos establecidos en la ley, para este caso en particular, no asegura el adecuado funcionamiento del establecimiento educacional, por las razones siguientes: a) Que, a la fecha la mayor parte de los estudiantes ha sido reubicado en otros establecimientos educacionales. b) Que, la subvención que recibiría el establecimiento con el número de alumnos que aún no son reubicados, veinte estudiantes según lo informado [...] hace inviable en el mediano plazo el funcionamiento básico del establecimiento. c) Que, el día 8 de marzo de 2016, el abogado de los apoderados informa mediante un «téngase presente» a la Corte de Apelaciones de Santiago, en virtud del recurso de protección que interpuso a favor de los alumnos, rol 17.538, que la sostenedora del Colegio San Nicolás había procedido a desmantelar el establecimiento educacional. d) Que, consta por las fiscalizaciones realizadas por la Dirección Regional de nuestro servicio, los días 10 de febrero y 7 de marzo de 2016, que el Colegio se encuentra cerrado y sin moradores. ${ }^{27}$

\section{Problemas en la configuración legal del administrador provisional de la Ley 20.529}

La Ley 20.529 entrega limitadas facultades al administrador provisional, por lo que en la práctica su figura adolece de la robustez económica para cumplir el mandato conferido por la ley. La deficiente técnica legislativa ha permitido también que el nombramiento del administrador provisional provoque una relación poco determinada y clara

ma.aspx?idPrograma $=46$.

27. Oficio núm. 0402, del 20 de abril de 2016, del Superintendente de Educación a la Directora Regional Metropolitana de la Superintendencia de Educación, disponible en http://bit.ly/2TFr87B. 
entre dicha figura y el órgano administrativo del cual depende: la Superintendencia de Educación.

\section{Legislación inadecuada para proveer facultades de provisión de recursos al administrador}

El administrador provisional de la Ley 20.529 ocupa la misma posición jurídica del sostenedor, sustituyéndolo para todos los efectos legales, ${ }^{28}$ por lo que no está autorizado, en general, para recibir recursos distintos o mayores a los que por ley le corresponden al primero. ${ }^{29}$ Debe gestionar el establecimiento educacional sujeto a su administración con los mismos recursos de que disponía el sostenedor original.

Dos casos explicitan lo señalado. Primero, tratándose de la causal que se refiere al atraso reiterado en el pago de remuneraciones o de las cotizaciones previsionales o de salud del personal del establecimiento, ${ }^{30}$ las facultades entregadas por la ley son insuficientes para resolver dichos problemas de gestión, pues no cuenta con financiamiento especial para ello y, además, porque no tiene potestad para solucionar deudas insolutas derivadas de obligaciones generadas con anterioridad a su nombramiento. ${ }^{31}$ Segundo, tampoco bastan las facultades conferidas al administrador cuando el nombramiento se debe a la causal señalada en la letra c) del artículo 89, esto es, cuando se haga imposible la mantención del servicio educativo a consecuencia de sanciones, medidas precauto-

28. El artículo 91 expresa: «Desde la fecha de designación del administrador provisional el sostenedor del establecimiento será sustituido por éste para todos los efectos legales, quedando inhabilitado para percibir la subvención educacional».

29. Excepto lo señalado en letra c) del artículo 92, incorporado por el artículo 29 de la Ley 20.880, sobre el Administrador Provisional y de Cierre de Instituciones de Educación Superior, «así como los que pudiere disponer la Ley de Presupuestos del Sector Público para asegurar la continuidad del servicio educacional del establecimiento correspondiente, solamente hasta el término del año escolar respectivo, siempre que concurran las siguientes circunstancias: i) que los aportes regulares que deba recibir no sean suficientes para financiar las remuneraciones del personal docente y asistentes de la educación, el pago de suministros básicos y demás gastos indispensables para su funcionamiento; ii) que los hechos que originaron el nombramiento del administrador provisional se produzcan durante el transcurso del año escolar respectivo, y iii) que dichos recursos se destinen íntegramente al pago relacionado con los gastos señalados en el numeral i) precedente.»

30. El artículo 89 expresa: «Sólo se podrá nombrar un administrador provisional en los siguientes casos [...] d) Cuando exista atraso reiterado en el pago de las remuneraciones o de las cotizaciones previsionales o de salud del personal del establecimiento. Se entenderá por atraso reiterado la mora total o parcial en el pago de dos meses consecutivos o de tres en un período de seis meses».

31. El inciso segundo del artículo 91 expresa: «Sin perjuicio de lo anterior, el sostenedor será responsable de todas las obligaciones que se hubieren generado en virtud del funcionamiento del establecimiento educacional con antelación a la designación del administrador provisional». El inciso 92..$^{\circ}$ del mismo artículo señala: «d) Pagar las obligaciones derivadas del servicio educacional desde el momento que asume sus funciones, con el límite de los recursos que reciba para su gestión, de acuerdo con las prioridades que establezca y procurando el buen desempeño del establecimiento educacional». 
rias, embargos, etcétera. ${ }^{32}$ En esta situación es natural preguntarse de qué manera este administrador designado por la autoridad administrativa, con las escasas facultades que la ley le confirió y con los recursos que recibe de un sostenedor técnicamente «quebrado», es capaz de resolver los problemas que, manteniéndose las mismas circunstancias que originaron su nombramiento, el legislador estimó posibles de solucionar transitoriamente hasta el término del año escolar.

En la Historia de la Ley 20.184 - como sabemos, antecedente directo e inmediato de las normas de la Ley 20.529, que regulan el actual administrador provisional- destacamos la intervención del senador Juan Antonio Coloma, de sobremanera asertiva:

Voy a colocarme en una situación real. Nos hallamos ante un establecimiento educacional virtualmente quebrado, que no está pagando las remuneraciones, que no entera las cotizaciones previsionales y de salud, que se encuentra con los servicios básicos suspendidos — estoy siguiendo la línea planteada por la iniciativa-, y que, además, puede tener embargos, ejecuciones o retiros de mobiliario. O sea, se trata de un sostenedor que está en situación dramática y en la cual el riesgo es que los alumnos pierdan el año escolar. Lo que se plantea mediante la iniciativa en debate es, para ese efecto, permitir el nombramiento de un interventor provisional, quien va a administrar la subvención. Mi impresión es que dicho personero recibirá una subvención que podrá alcanzar para, en teoría, asegurar la continuidad del servicio educacional, pero no para pagar las cotizaciones previsionales atrasadas, ni para levantar los embargos, ni para impedir las ejecuciones o retiros de mobiliario que el mismo proyecto señala. Porque [...] al final la norma propuesta dice: «El funcionario encargado tendrá las facultades consignadas en el artículo 2.132 del Código Civil». El referido precepto dispone: «El mandato no confiere naturalmente al mandatario más que el poder de efectuar los actos de administración...». O sea, por mandato del Código Civil, ese funcionario sólo podrá cobrar la subvención. Pero, en esta lógica, no veo de dónde va a obtener los recursos para enfrentar el año escolar en forma razonable y con un mecanismo distinto del aplicado por el sostenedor original. Éste no suele ser un problema de caja, sino de deuda» (BCN, 2018a: 45-46).

Y recordemos el citado oficio del Superintendente de Educación, núm. 409, sobre el caso del Colegio San Nicolás, que señala en la letra b) del número 7:

Que, la subvención que recibiría el establecimiento con el número de alumnos que aún no son reubicados, veinte estudiantes según lo informado por el Departamento Provincial de Educación Norte, hace inviable en el mediano plazo el funcionamiento básico del establecimiento. ${ }^{33}$

32. La letra c) del artículo 89 indica que solo se podrá nombrar un administrador provisional en los siguientes casos: «Cuando, por razones imputables al sostenedor, se haga imposible la mantención del servicio educativo a consecuencia de sanciones, medidas precautorias, embargos, ejecuciones o retiros que afecten al establecimiento educacional o a su mobiliario».

33. Oficio núm. 0402, del 20 de abril de 2016, del Superintendente de Educación a la Directora Regional Metropolitana de la Superintendencia de Educación, disponible en http://bit.ly/2TFr87B. 
Luego, además de no contar con financiamiento especial, este administrador carece, en principio, de una atribución que le permita liberar las retenciones de subvención efectuadas por las Secretarías Regionales Ministeriales de Educación, lo que ayudaría de sobremanera al cumplimiento de su mandato. En efecto, la norma introducida por la Ley 20.80o, que crea el Administrador Provisional y Administrador de Cierre de Instituciones de Educación Superior, cuyo propósito era precisamente dotar a esta figura de más recursos, es, por un lamentable error de referencia, de difícil aplicación. Lo anterior, pues se hace mención equivocadamente a la norma del inciso segundo del artículo 54 del Decreto con Fuerza de Ley núm. 2, de 1998, del Ministerio de Educación. Sin embargo, dicha disposición se refiere a la ejecución de la retención como medida precautoria impuesta en el marco de un procedimiento administrativo sancionador instruido por los Secretarios Regionales Ministeriales (es decir, al artículo 53, que está derogado según el número 11 del artículo 113 de la Ley 20.529). De conformidad a lo dispuesto en la Ley 20.529, dichos procedimientos son ahora de competencia exclusiva de la Superintendencia de Educación. ${ }^{34}$

En rigor, la norma que habilita la retención de la subvención por un monto equivalente a las cotizaciones previsionales y de salud que los sostenedores mantengan impagas, es el artículo 7 de la Ley 19.609 de $1999,{ }^{35}$ que permite efectuar anticipos del Fondo Común Municipal, norma a la que debió referirse el proyecto de ley, y que debió ser aludida en la Ley 20.529 y no a la disposición que se cita en su artículo 91 inciso 4 (el ya aludido artículo 54 del Decreto con Fuerza de Ley núm. 2, de 1998). En este mismo sentido, también se ha pronunciado la jurisprudencia administrativa ${ }^{36}$ y judicial. ${ }^{37}$

34. El inciso cuarto del artículo 91 de la Ley 20.529 expresa: «Mientras dure la administración provisional de un establecimiento específico, excepcionalmente y por resolución fundada del Ministerio de Educación con la visación del Ministro de Hacienda, se podrán dejar sin efecto las retenciones de pago adoptadas por aplicación de lo previsto en el inciso segundo del artículo 54 del Decreto con Fuerza de Ley núm. 2, de 1998, del Ministerio de Educación, que fija el texto refundido, coordinado y sistematizado del Decreto con Fuerza de Ley núm. 2, del mismo Ministerio, de 1996, sobre Subvención del Estado a Establecimientos Educacionales».

35. Señala: «A contar del primer día del mes siguiente al de la fecha de publicación de la presente ley, en caso que se produzca un atraso en el integro de imposiciones previsionales que se devenguen a partir de esa fecha por parte de los sostenedores de establecimientos educacionales subvencionados, el Ministerio de Educación deberá retener de los recursos que les corresponda percibir por aplicación del Decreto con Fuerza de Ley núm. 2, de 1998, del Ministerio de Educación [...] un monto equivalente a las cotizaciones que éstos deban pagar».

36. El Dictamen 21.529 de la Contraloría General de la República señala: «Al respecto, cabe señalar que la Ley 19.609, publicada en el Diario Oficial del 2 de junio de 1999, que permite efectuar anticipos del Fondo Común Municipal en los casos que indica, dispone en el inciso primero de su artículo 7 que...».

37. El considerando decimoquinto de la sentencia rol 911-2015 de la Corte de Apelaciones de Punta Arenas, un fallo emanado el 20 de enero de 2016 , en autos sobre recurso de protección, señala: «...y, en este entendido, la actuación tanto de la Secretaria Ministerial de Educación como la del Coordinador Nacional de Subvenciones no ha sido arbitraria, ello porque el artículo 7 de la Ley 19.609 en armonía con el Decreto con Fuerza de Ley núm. 2 de 1998 del Ministerio de Educación [...] deviene que en el caso de ocasionarse demora en el íntegro de las imposiciones previsionales devengadas, por parte de los sostenedores de esta- 
No obstante, la misma Contraloría ha validado errores de técnica legislativa consistentes en errores de referencias a otras leyes o más precisamente, de vigencia o derogación por errores de transcripción de las normas, recurriendo al efecto al espíritu del legislador, por aplicación los artículos 19 y 21 del Código Civil. ${ }^{38}$

Pese a todo lo afirmado con anterioridad, y aunque en virtud de Dictamen 31.380 de la Contraloría General de la República pudiese aplicarse el inciso cuarto del artículo 91 de la Ley 20.529, no es posible concebir razonablemente cómo, aun dejadas sin efecto por el administrador provisional las retenciones referidas, este interventor pueda utilizar esos recursos liberados, si se considera la restricción temporal que le impone el artículo 91 inciso segundo de la Ley 20.529..$^{39}$

Del mismo modo, la modificación introducida en el artículo 92 de la Ley 20.529 por el artículo 29, número 3 , letra a), de la Ley 20.800 de $2014,{ }^{40}$ y que reemplaza una parte de la letra c), si bien establece que el administrador provisional podrá percibir y administrar los recursos que pudiere disponer la Ley de Presupuestos del Sector Público, dicha regulación es imprecisa e insuficiente, en tanto no establece una cantidad fija de recursos ni señala a qué institución se imputarán los mismos, y tampoco señala

blecimientos educacionales subvencionados, el Ministerio de Educación se encuentra en la obligación de retener, de los recursos que a dichas personas les corresponde percibir».

38. Véase el Dictamen 31.380 de la Contraloría General de la República, emitido el 17 de agosto de 2000, se trata de una consulta del Indap, que «solicita un pronunciamiento acerca de la vigencia del precepto contenido en el núm. 4 del artículo 3 de la Ley Orgánica de ese servicio, núm. 18.910, el cual podría encontrarse derogado por el artículo 78 de la Ley 19.253 [...] La entidad recurrente adjunta un informe del Fiscal de la misma, en el que se sostiene que la disposición contenida en el referido núm. 4 se encontraría vigente, por cuanto su derogación se habría producido por un error de transcripción en la redacción del referido artículo 78 de la Ley 19.253». Y la Contraloría señala: «En estas condiciones, es dable anotar que la intención del legislador no ha sido otra que derogar la disposición que entregaba atribuciones al referido Instituto para regularizar la propiedad indígena [...] de manera que no cabe duda que cuando este precepto abroga el núm. 4, en realidad su propósito es derogar el núm. 6 del actual texto en vigor [...] De las consideraciones anteriores aparece que no resulta suficiente para interpretar el sentido del mencionado artículo 78 el tenor literal de dicha disposición, debiéndose, en consecuencia, conforme a lo dispuesto en el inciso segundo del artículo 19 y 22 del Código Civil, recurrir a su intención o espíritu y al contexto de la ley».

39. No debemos olvidar que el sostenedor original es el responsable de todas las obligaciones generadas con anterioridad al nombramiento del interventor, pudiendo solo el administrador provisional pagar las deudas hacia lo futuro.

40. El texto de esta norma es: «Reemplázase, en la letra c), del artículo 92, de su inciso segundo, la expresión «y otros aportes regulares que entregue el Estado», por el siguiente texto: «otros aportes regulares que entregue el Estado, así como los que pudiere disponer la Ley de Presupuestos del Sector Público para asegurar la continuidad del servicio educacional del establecimiento correspondiente, solamente hasta el término del año escolar respectivo, siempre que concurran las siguientes circunstancias: i) que los aportes regulares que deba recibir no sean suficientes para financiar las remuneraciones del personal docente y asistentes de la educación, el pago de suministros básicos y demás gastos indispensables para su funcionamiento; ii) que los hechos que originaron el nombramiento del administrador provisional se produzcan durante el transcurso del año escolar respectivo, y iii) que dichos recursos se destinen íntegramente al pago relacionado con los gastos señalados en el numeral i) precedente»». 
el procedimiento para obtenerlos ni bajo qué circunstancias el Ministerio de Hacienda podría autorizarlos, por lo que no se otorga más financiamiento, sino meros recursos eventuales y, en general, para el próximo ejercicio presupuestario. En esta misma lógica, su disposición sigue siendo eventual al señalar la norma de manera textual: «...así como los que pudiere disponer la Ley de Presupuestos del Sector Público» (artículo 92, Ley 20.529).

\section{Defectos en la técnica legislativa: Una perspectiva institucional}

Ninguna de las facultades otorgadas a este administrador temporal permiten hacer frente a uno de los problemas más complejos de abordar, y que se presenta en la mayoría de los casos. Este es el cierre intempestivo de locales escolares por ausencia injustificada del sostenedor o por abandono de su proyecto educativo. ${ }^{41}$ Pues si este se encontrase cerrado, ni siquiera podría ingresar a dicho establecimiento para cumplir su cometido sin incurrir en una eventual responsabilidad penal, al no tener este administrador provisional, o la autoridad administrativa que lo designó, la atribución legal para requerir el auxilio de la fuerza pública ${ }^{42}$ y forzar el ingreso al recinto. Así las cosas, no se ve el sentido de la aplicación de esta técnica de intervención administrativa.

Y sobre el caso real de análisis, recordemos lo que expone la autoridad en su mentado Oficio núm. 409, letras d) y c) del punto 7, en donde señala:

"Que, consta por las fiscalizaciones realizadas, que el Colegio se encuentra cerrado y sin moradores» (Cámara de Diputados de la República de Chile, 2016: número 7, letra d), y «Que, el abogado de los apoderados informa mediante un 'téngase presente' a la Corte de Apelaciones de Santiago [...] que la sostenedora del Colegio San Nicolás había procedido a desmantelar el establecimiento educacional. ${ }^{43}$

Como se puede apreciar, frente a un Colegio cerrado y sin muebles, y aunque concurran las causales que hacen proceder su designación, la pregunta parece inevitable: ¿Qué sentido tiene en este caso el nombramiento del administrador provisional?

Por otra parte, tampoco podría desempeñar fielmente su mandato frente a obligaciones como la de rendir cuenta pública de los recursos entregados al sostenedor en el año anterior - actualmente ausente-, en tanto no tendría acceso a la información

41. El artículo 89 de la Ley 20.529 indica que solo se podrá nombrar un administrador provisional, en los siguientes casos: letra b), «Cuando el representante legal o el administrador de la entidad sostenedora se ausente injustificadamente, poniendo en riesgo la continuidad del año escolar», y letra g), «Cuando un sostenedor abandone, durante el año escolar, su proyecto educativo, dejando de prestar el servicio educacional en el establecimiento de su dependencia».

42. El inciso segundo del artículo 4 de la Ley 18.961 señala: «Carabineros, asimismo, prestará a las autoridades administrativas el auxilio de la fuerza pública que éstas soliciten en el ejercicio legítimo de sus atribuciones».

43. Oficio núm. 0402, del 20 de abril de 2016, del Superintendente de Educación a la Directora Regional Metropolitana de la Superintendencia de Educación, disponible en http://bit.ly/2TFr87B. 
que se requiere para tal efecto. Lo anterior, coloca al administrador en una situación de incumplimiento normativo. En efecto, la normativa sólo contempla que el administrador pueda solicitar al sostenedor toda la información que estime necesaria para llevar a cabo su función. Pero dicha atribución es totalmente insuficiente en estos casos, pues en rigor la ley sólo contempla la facultad de la Superintendencia de Educación de incoar un procedimiento sancionatorio por eventual infracción a la Ley 20.529, en contra del sostenedor que no permita el acceso al establecimiento o no entregue la información solicitada. ${ }^{44}$

A lo anterior debe agregarse que los requisitos para ser nombrado administrador provisional, ya sea persona natural o jurídica, ${ }^{45}$ son incluso más laxos que los exigidos para ser sostenedor. ${ }^{46}$ Por lo demás, significa un retroceso en materia de protección del patrimonio público entregado, que ha avanzado hacia la exigibilidad de un administrador permanente que tenga la calidad de persona jurídica de derecho público o de derecho privado sin fines de lucro, cuyo objeto social único sea la educación. ${ }^{47}$

44. El inciso tercero del artículo 22 de Decreto Supremo núm. 538 del año 2013 del Ministerio de Educación señala: «En caso de que el sostenedor no realizara la entrega de la información solicitada o lo hiciera de manera inexacta o incompleta, o no permita el acceso al establecimiento educacional, el administrador provisional denunciará este hecho a la Superintendencia, quien podrá en virtud de los antecedentes expuestos, iniciar un procedimiento administrativo por eventual infracción a las normas establecidas al respecto en la Ley 20.529".

45. El Decreto Supremo núm. 538 del Ministerio de Educación señala: «Artículo 3. El postulante, persona natural, interesado en integrar este Registro, deberá acompañar a su solicitud, debidamente firmada e individualizada, los siguientes documentos, a saber: 1) Copia simple de la cédula de identidad; 2) $\mathrm{Cu}$ rrículum Vitae; 3) Certificado de obtención de un Título Profesional o Licenciatura [...]; 4) Certificado de antecedentes; 5) Declaración jurada ante Notario en la que el postulante exprese: a) No estar afecto a ninguna de las inhabilidades e incompatibilidades a que se refiere la Ley 20.529, Ley 18.575, Orgánica Constitucional de Bases Generales de la Administración del Estado [...] b) Que los antecedentes que se adjuntan son auténticos, fidedignos, veraces y plenamente vigentes [...] 6) Todos aquellos antecedentes, documentos u otros, que permitan acreditar una experiencia de a lo menos 5 años, en gestión de establecimientos educacionales como, docente, directivo o sostenedor. Artículo 4. En el caso del postulante persona jurídica, los documentos que se indican precedentemente, se requerirán respecto de representantes legales y/o administradores de dicha institución, según corresponda».

46. El artículo 2 del Decreto con Fuerza de Ley núm. 2 de 1998 del Ministerio de Educación expresa: «El representante legal y el administrador de entidades sostenedoras de establecimientos educacionales deberán cumplir con los siguientes requisitos: i) Estar en posesión de un título profesional o licenciatura, de al menos 8 semestres, otorgado por una universidad o instituto profesional del Estado o reconocido por éste; ii) No haber sido sancionado con las inhabilidades para ser sostenedor, por haber cometido alguna de las infracciones graves señaladas en los artículos 50 de la presente ley y 76 de la ley que crea el Sistema Nacional de Aseguramiento dela Calidad de la Educación; iii) No haber sido condenado por crimen o simple delito, especialmente por aquellos a que se refieren el Título VII del Libro II del Código Penal y la Ley 20.00o, que sanciona el tráfico ilícito de estupefacientes, ni haber sido condenado con la pena de inhabilitación absoluta perpetua para cargos, empleos, oficios o profesiones ejercidos en ámbitos educacionales o que involucren una relación directa y habitual con personas menores de edad [...] artículo 39 bis del Código Penal».

47. El artículo 6 del Decreto con Fuerza de Ley núm. 2 de 1998 del Ministerio de Educación señala: «Para 


\section{Relación constantemente indefinida entre la Superintendencia de Educación y Administración Provisional}

La Ley 20.529 no contempla un estatuto jurídico especial para el período de administración de este mandatario que permita fiscalizarlo de manera diferenciada por parte de la Superintendencia de Educación, procurando en todo caso siempre el cumplimiento de la normativa educacional esencial, pero estableciendo un distingo razonable atendidas las particularidades inherentes a la gestión de un establecimiento intervenido de manera excepcional, en virtud de una fuerte crisis institucional.

Luego, en casos en que proceda el financiamiento complementario por parte de la Superintendencia de Educación en la remuneración del administrador, deberá éste entregar una boleta de honorarios al órgano de la administración que lo designó, ${ }^{48}$ rindiendo cuenta de la gestión que justifica el desembolso, por lo que se produce una relación al menos confusa entre el «fiscalizado» y el ente fiscalizador, pareciendo el primero un funcionario del segundo, más que una figura independiente que reemplaza al sostenedor y mantiene su autonomía.

\section{Administrador provisional (o de cierre) de educación escolar}

Ponemos de manifiesto desde ya que, por las razones que se expondrán a continuación, es posible sostener con meridiana propiedad que el administrador provisional de la Ley 20.529 es, en general, un administrador de cierre, y solo excepcionalmente un administrador provisional, en el caso del artículo 94. Y para hacerse cargo de lo aseverado, se analizará primero, en lo pertinente, la normativa del interventor provisional escolar y la historia de su ley actual y de la Ley 20.184, para luego cotejarlas con las normas atingentes de la Ley 20.800. ${ }^{49}$

que los establecimientos de enseñanza puedan impetrar el beneficio de la subvención, deberán cumplir con los siguientes requisitos: [...] Tratándose de sostenedores particulares, éstos deberán estar constituidos como corporaciones o fundaciones de derecho privado sin fines de lucro de acuerdo al Título XXXIII del Libro I del Código Civil, como personas jurídicas de derecho público, como corporación o entidad educacional en los términos de esta ley o como otras personas jurídicas sin fines de lucro establecidas por leyes especiales».

48. El artículo 16 del Decreto Supremo del Ministerio núm. 538 de Educación de Chile define que «en el caso de recibir el complemento de la remuneración señalado, deberá entregar otra boleta de honorarios en la dirección nacional de la Superintendencia de Educación».

49. Ley que además contiene normas que modificaron otras disposiciones legales del administrador provisional de la Ley 20.529. 


\section{Única hipótesis en que el administrador provisional de la Ley $20.529 \mathrm{o}$ pera como un administrador provisional. Caso del artículo 94}

El artículo 94 de la Ley $20.529^{50}$ señala que el administrador provisional tendrá facultades para reestructurar un establecimiento educacional que se encuentre en las condiciones que establece el artículo 89, letra a), es decir, desempeño insuficiente por cuatro años consecutivos, siempre que se trate de establecimientos municipales, y que no existan establecimientos cercanos que impartan el mismo nivel educativo con vacantes. Y luego nos expresa, en su segundo inciso, que en el caso de la reestructuración: «el administrador provisional se hará cargo de las obligaciones legales hasta la entrega del establecimiento educacional a la municipalidad o corporación respectiva, o a la entidad creada por ley que corresponda, la que deberá materializarse dentro del plazo de tres años, contado desde la fecha de su nombramiento».

\section{Administrador de Cierre}

La Historia de la Ley 20.529 refuerza lo señalado respecto a la naturaleza de administrador de cierre de este interventor. La otrora Ministra de Educación Mónica Jiménez, señaló en la Comisión de Educación de la Cámara de Diputados lo siguiente:

Si un establecimiento educacional es objeto de sanciones graves que ameriten la pérdida del reconocimiento oficial, o si por razones sobrevinientes no puede seguir funcionando regularmente [...]: Si el establecimiento es particular subvencionado: El administrador deberá tomar todas las medidas para dar adecuado cierre al establecimiento (BCN, 2018b: 64-65).

Luego aborda el caso de los establecimientos municipales, señalando:

Si el establecimiento es municipal: El administrador provisional se hará cargo de proceder al cierre del establecimiento [...] Si existen establecimientos gratuitos de mejor desempeño en la comuna o comunas cercanas (BCN, 2018b: 65).

Y si no existen, expresa: «[El administrador provisional] procederá a la reestructuración del establecimiento. Tendrá un plazo máximo de 2 años, luego del cual devolverá el establecimiento a su sostenedor» (BCN, 2018b: 65).

En virtud de lo recién analizado, cuesta comprender la denominación de provisional

50. Señala: «El administrador provisional tendrá facultades para reestructurar un establecimiento educacional que se encuentre en las condiciones que establece el artículo 89, letra a), siempre que se trate de establecimientos educacionales administrados por municipalidades, sea directamente o por sus corporaciones municipales, o administrados por otras entidades creadas por ley, y no existan establecimientos cercanos que impartan el mismo nivel educativo, ordenados en mejor categoría y que cuenten con vacantes. En el caso de la reestructuración a que se refiere el inciso anterior, el administrador provisional se hará cargo de las obligaciones legales hasta la entrega del establecimiento educacional a la municipalidad o corporación respectiva, o a la entidad creada por ley que corresponda, la que deberá materializarse dentro del plazo de tres años, contado desde la fecha de su nombramiento». 
que la Ley 20.529 otorga a este administrador, pues, como se analizó, en la mayoría de los casos opera como un interventor de cierre, y en solo una hipótesis como administrador provisional, que es la situación que regula el artículo 94 de la ley en comento.

Otro antecedente lo encontramos en la Historia de la Ley 20.184, antecedente más directo del administrador de la Ley 20.529. En la página 59, el senador Juan Antonio Coloma hace una reflexión en donde queda de manifiesto que este administrador, el de la Ley 20.184, que también se denominó «provisional», fue sin duda un interventor de cierre. Expresa lo siguiente:

Si, por ejemplo, la subvención es 100; las deudas, 300, y lo necesario para mantener funcionando el establecimiento, 100, seguirán - lo dijo un señor senador que me antecedió- los embargos, van a continuar las cotizaciones impagas, etcétera. Por eso, no sé si aquí procede buscar una fórmula al estilo de lo que sucede en ciertas empresas con la continuidad de giro - como me «sopló» el senador señor Orpis—, en el sentido de dar al administrador una facultad adicional o generar alguna figura que le permita conseguir el funcionamiento normal del establecimiento. Porque, más allá de la intención que anima a este proyecto, al final se puede generar un problema mucho más grave, pues se nombrará al administrador provisional, la gente pensará que eso es la solución, pero se seguirán cobrando las deudas previsionales y otras, sin que haya posibilidad alguna de pagarlas» (BCN, 2018a: 46).

\section{Concepto de administración provisoria}

Un tercer argumento, y que, junto con el texto expreso de ley y su historia, refuerza lo ya expresado, es el concepto mismo de administración provisional o provisoria. En la sentencia del Tribunal Constitucional rol 2731-14, considerando $172 .^{\circ}$, se hace referencia a la cualidad "provisoria» del administrador de educación superior:

Aunque parezca evidente, puesto que debe ser la palabra más mencionada en este proyecto de ley, cabe consignar que la dimensión provisoria admite por corolario que la administración titular permanece [...] Primero, la administración titular sólo se «suspende». ${ }^{51}$

Y como acabamos de estudiar, en general, el establecimiento debe cerrarse, existiendo en una sola hipótesis, la del artículo 94, la devolución del establecimiento al sostenedor (énfasis añadido).

Pero la conclusión más demoledora que resulta del análisis de la historia de la ley y de la actual norma es que nunca, y en ningún caso, el administrador de un establecimiento particular subvencionado será provisional.

Recordemos el caso ya referido del Colegio San Nicolás, específicamente en la intervención que el dirigente del Centro de Padres realiza en la Comisión de Educación de la Cámara de Diputados:

51. Se remite al actual artículo 17 de la Ley 20.800 de 2014. 
Hablar de que el proyecto educativo no es viable y que la mejor solución sea cambiar a los niños [...] porque si este colegio puede ser un pionero en solucionar un problema que a lo mejor se les va a venir con la reforma de educación de aquí a final de año... ${ }^{52}$

Si aplicamos la solución que él pide, nunca podrá tener continuidad el apreciado proyecto educativo de su Colegio y, tampoco podrá ser pionero o modelo de solución a cualquier problema de reforma legal pues, indefectiblemente, el establecimiento será cerrado por el administrador provisional.

\section{El administrador provisional de la Ley 20.529 no admite prórroga, y su símil de educación superior sí otorga esa posibilidad}

Finalmente, un cuarto y último argumento en este sentido es el inciso segundo del artículo 87 de la Ley 20.529 que señala que el administrador provisional durará en su cargo sólo hasta el término del año escolar en curso (salvo lo establecido en el inciso segundo del artículo 94). Y por su parte, el artículo 12 de la Ley 20.800 expresa con claridad: «El administrador provisional durará en su cargo un año, plazo prorrogable por una sola vez hasta por igual período, cuando ello sea necesario».

Podemos ver cómo entonces, por una parte, al admitir prórroga el interventor en educación superior refuerza la diferencia entre un administrador provisional y uno de cierre. De esta forma, al ser susceptible de prórroga, se produce el efecto de administración provisional propiamente tal, ese que solicitaba en su oportunidad el senador Coloma para el «hermano menor» del administrador de la Ley 20.529 (Ley 20.184, 2007), al señalar: «Por eso, no sé si aquí procede buscar una fórmula al estilo de lo que sucede en ciertas empresas con la continuidad de giro» (BCN, 2018a: 46).53

\section{Conclusiones}

En el presente trabajo se esbozó la siguiente tesis: la deficiente técnica legislativa que aplicó el legislador en la configuración del administrador provisional de la Ley 20.529,

52. Video del canal de televisión de la Cámara de Diputados, disponible en http://www.cdtv.cl/Programa.aspx?idPrograma=46, minuto 1:32:06.

53. La ley 20.529 no hace la diferencia formal entre ambos tipos de administrador, no obstante existir en la ley ambas figuras. De esta manera, el artículo 4 de la Ley 20.800 es esencial para entender la diferencia con el interventor escolar. Primero, hace referencia a la resolución de término de la investigación preliminar, que es aquella que instruye el Ministerio de Educación cuando detecta diversos incumplimientos en la institución de educación superior. También decretará la medida frente a la infracción grave de los estatutos o escritura social, dependiendo del caso. Y en la mentada resolución de término de la investigación preliminar, el Ministerio de Educación puede, fundadamente y atendidas las características de la institución y la naturaleza y gravedad de los problemas constatados, adoptar una de las siguientes medidas: a) ordenar la elaboración de un plan de recuperación, ante incumplimientos graves; b) nombrar un administrador provisional si se configuran las causales previstas en el inciso primero del artículo 6; y c) dar inicio al procedimiento de revocación del reconocimiento oficial, en caso de que se constaten problemas de una entidad mayor. De decretarse la revocación, se procederá al nombramiento de un administrador de cierre. 
redunda (y redundará) necesariamente en la pérdida de su eficacia normativa. Y para justificar los argumentos desarrollados, se trabajó de forma teórica y también empírica.

Dicho esto, y en virtud del desarrollo del trabajo, es posible señalar con razonable certeza que existen muy buenos argumentos jurídicos y fácticos, y en un número considerable, como para sostener académicamente la tesis que se desarrolló en este artículo. Los principales fundamentos esgrimidos, pueden resumirse en los siguientes:

- El administrador de la Ley 20.529 pierde su sentido de existencia normativa, como se pudo constatar, por lo poco eficaz que puede resultar su intervención ante un establecimiento escolar en crisis económica y de cierre inminente, debido a que, en general, recibirá los mismos recursos que su antecesor.

- Quedó meridianamente claro que los esfuerzos del Poder Ejecutivo por perfeccionar esta figura, mediante la modificación de la Ley 20.529, resultaron ser muy poco certeros en dotar de nuevos recursos económicos al administrador provisional. Resultó lamentablemente constatar cómo, nuevamente, se volvió a fallar en la técnica legislativa.

- Y vimos cómo ante una situación de ocurrencia frecuente, como es el cierre intempestivo de un local escolar, la normativa de la Ley 20.529, no contempló ninguna solución para que el interventor nombrado pudiese forzadamente entrar a un establecimiento cerrado.

- Y, no obstante, ser excepcional la intervención de esta figura de administración, tampoco el legislador estableció norma alguna que se hiciera cargo de esta realidad distinta, debiendo por tanto el interventor, enfrentar la actividad fiscalizadora en igualdad de condiciones que otros establecimientos educativos.

- Por otra parte, se constató fundadamente que el administrador provisional, en general, no actúa como tal, sino en un solo caso (hipótesis del artículo 94 de la Ley 20.529), operando en todas las demás situaciones como un verdadero administrador de cierre. Y como esta poca claridad genera confusión en el sistema escolar, indirectamente se ve afectada también la eficacia de la norma.

- Y la conclusión más importante del presente trabajo es necesariamente la siguiente: en ninguna hipótesis, el administrador provisional de la Ley 20.529, en el caso de un establecimiento particular subvencionado, es realmente provisional, sino que, por el contrario, es de cierre, por lo que su designación no es útil para sus propósitos.

Finalmente, es menester señalar un asunto neurálgico que es posible extraer de todo lo ya desarrollado, y que dice relación con la necesaria, ineludible e impostergable tarea de adecuación normativa que debe realizar el legislador en lo sucesivo. De lo contrario, una institución que se justifica plenamente en la protección al derecho constitucional a la educación perderá, en definitiva, toda utilidad. 
Parece adecuado, aunque no sea el objeto principal de este artículo, realizar de igual manera algunas propuestas, muy generales, de mejoras normativas a la Ley 20.529:

- En primer lugar, es necesario establecer muy específicamente la distinción entre el administrador provisional y de cierre en la Ley 20.529, pues, aunque existen dos tipos de interventores, solo el administrador provisional, que es la excepción, aparece claramente visualizado. En este sentido, se sugiere seguir, con las adecuaciones del caso, la forma en que la Ley 20.800 aborda ambas instituciones.

- También es una tarea prioritaria perfeccionar las normas que pretendieron otorgar más recursos al administrador provisional. En relación con el artículo 91 inciso cuarto, junto con realizar adecuadamente la referencia a la norma del artículo 7 de la Ley 19.607, debe establecerse una excepción, para este caso concreto, a la restricción que le impide al administrador pagar deudas contraídas con anterioridad a su nombramiento, para que, de esta manera, pueda operar con total eficacia la idea consagrada en la norma.

- Con el mismo objeto, se debe precisar aún más la modificación introducida en el artículo 92 de la Ley 20.529. Más allá de establecer las restricciones del caso, y que por lo demás existen, se debe señalar desde qué repartición pública se entregará el eventual nuevo financiamiento que pueda otorgar la Ley de Presupuestos, quién debe solicitarlos y mediante qué procedimiento y en qué plazos será posible obtenerlos.

Las demás propuestas de perfeccionamiento normativo pueden desprenderse con facilidad del contenido del presente trabajo, especialmente si se hace el ejercicio de analizar en términos positivos las deficiencias detectadas y mencionadas.

Para finalizar, es importante plantear la necesidad de contar con más publicaciones académicas sobre esta interesante temática. Son necesarios artículos académicos básicos, descriptivos, pero también otros que se hagan cargo de discusiones pendientes y más complejas, como, por ejemplo: ¿puede un administrador provisional ser nombrado en más de un establecimiento educacional? Y si es de dependencia municipal, ¿puede el interventor reemplazar la figura del jefe del Departamento de Administración de Educación Municipal o del Secretario General de una Corporación de Educación Municipal?

\section{Referencias}

BCN, Biblioteca del Congreso Nacional (2018). Historia de la Ley 20.184. Faculta la designación de Administrador Provisional en establecimientos Educacionales Subvencionados en casos que indica. Disponible en http://bit.ly/2FhlJ2y.

-. (2018b). Historia de la Ley 20.529. Sistema Nacional de Aseguramiento de la Calidad de la Educación Parvularia, Básica y Media y su fiscalización. Disponible en http:// bit.ly/2scD8Sv. 
FerradA, Juan Carlos y Flavio Quezada (2017). «Transferencia de inmuebles educacionales por el solo ministerio de la ley y autonomía local». En Fabián Huepe Artigas y Francisco Santibáñez Yáñez (coordinadores), Sistema Municipal chileno. Desafíos y perspectivas para el siglo XXI. Actas de las XII Jornadas de Derecho Administrativo. Concepción, 2015. Santiago: Librotecnia.

\section{Sobre el autor}

Carlos Rivera Hernández es abogado y licenciado en Ciencias Jurídicas y Sociales de la Universidad Academia de Humanismo Cristiano. Es magíster en Derecho Público de la Universidad Finis Terrae. Ha sido jefe nacional del Departamento Jurídico de la Superintendencia de Educación. Actualmente se desempeña como jefe del Departamento de Asesoría Jurídica y fiscal administrativo del Instituto Nacional de la Juventud. Su correo electrónico es hernandez.carlos7799@gmail.com. 
